\title{
Article
}

Arq Neuropsiquiatr 2010;68(1):44-47

\section{Cross-cultural adaptation and validation of ALS Functional Rating Scale-Revised in Portuguese language}

\author{
Keyte Guedes', Cecília Pereira', Karina Pavan², \\ Berenice Cataldo Oliveira Valério ${ }^{3}$
}

\begin{abstract}
The aim of this study is the cross-cultural, as well as to validate in Portuguese language the Amyotrophic Lateral Sclerosis Functional Rating Scale - Revised (ALSFRS-R). We performed a prospective study of individuals with amyotrophic lateral sclerosis (ALS) clinically defined. The scale, after obtaining the final version in Portuguese, was administered in 22 individuals and three weeks after re-applied. There were no significant differences between the application and reapplication of the scale $(p=0.069)$. The linear regression and internal consistency measured by Pearson correlation and alpha Conbrach were significant with $r=0.975$ e $\alpha=0.934$. The reliability test-retest demonstrated by intraclass correlation coefficient was strong with ICC $=0.975$. Therefore, this version proved to be applicable, reliable and easy to be conducted in clinical practice and research. Key words: amyotrophic lateral sclerosis, scales, cross-cultural comparison, translating.
\end{abstract}

\section{Adaptação transcultural e validação da ALS Functional Rating Scale-Revised para a língua portuguesa}

\section{RESUMO}

O objetivo deste estudo foi realizar a adaptação transcultural, bem como validar na língua portuguesa a Amyotrophic Lateral Sclerosis Functional Rating Scale - Revised (ALSFRS-R). Foi realizado um estudo prospectivo com indivíduos com esclerose lateral amiotrófica clinicamente definida. A escala, após a obtenção da sua versão final em português, foi aplicada em 22 indivíduos em dois momentos com intervalo de três semanas. Não foram observadas diferenças significativas entre a aplicação e reaplicação da escala $(p=0,069)$. A fidedignidade e a consistência interna mensuradas pela correlação de Pearson e alfa de Conbrach foram significativos com $r=0,975$ e $\alpha=0,934$, respectivamente. A confiabilidade evidenciada pelo coeficiente de correlação intraclasse foi forte com ICC $=0,975$. Portanto, a versão em português da ALSFRS-R demonstrou ser reprodutível, confiável, de fácil aplicação e compreensão para prática clínica e pesquisa.

Palavras-chave: esclerose lateral amiotrófica, escalas, comparação transcultural, tradução.

Amyotrophic lateral sclerosis (ALS) is a degenerative disease of unknown cause ${ }^{1}$ that presents motor, bulbar and respiratory dysfunctions, the last of which is the principal cause of death ${ }^{2-4}$. Within clinical evaluations that detail mortality, pulmonary function, muscular strength and incapacity, there is the Amyotrophic Lateral Sclerosis Functional Rating Scale - ALSFRS ${ }^{5-7}$.
The ALSFRS or its revised version (ALSFRS-R) is functional assessment disease-specific functional rating scale, considered clinically meaningful and predicts survival time ${ }^{2,8}$. Nevertheless, the handicap of the ALSFRS is the absence of a respiratory rating scale. For this reason, the ALSFRS-R was developed in 1999 to evaluate this function without altering the pro-
Keyte Guedes da Silva Rua Fernando Pessoa, 595 02670-000 - São Paulo SP - Brasil E-mail: keyteguedes@ig.com.br

Received 13 April 2009 Received in final form 01 September 2009 Accepted 08 September 2009
Irmandade Santa Casa de Misericórdia de São Paulo (ISCMSP), São Paulo SP, Brazil: 1Physiotherapist, Neurofuncional Specialists; ${ }^{2} \mathrm{MD}$, Physiotherapist, Neurofuncional Specialists; ${ }^{3}$ Medical Neurologist, Head of the Neuromuscular Diseases Clinic. 
priety, utility and validity of the original scale ${ }^{9}$. The ALSFRS-R is a validated rating instrument, linear and reliable when administered over the telephone and when administered to the caregiver ${ }^{10}$ resulting in more complete assessments and consistent ${ }^{11}$. In Brazil, we do not have any specific evaluation instrument for functionality in patients with ALS. Being as such, the necessity of monitoring the evolution of patients and the search for scientific evidence upon which to base the different types of therapeutic treatment demonstrates the relevance of this study.

In view of the foregoing, the aims of this study were to culturally adapt and further validate in the Portuguese language the Amyotrophic Lateral Sclerosis Functional Rating Scale - Revised (ALSFRS-R/BR).

\section{METHOD}

This study is a prospective analysis composed of 22 individuals with specific estimate the proportion of population with a confidence level of 90 and maximum error of $10 \%$. Individuals were from the ambulatory department for neuromuscular diseases of the hospital "Irmandade da Santa Casa de Misericórdia de São Paulo" (ISCMSP) and were selected after approval from the Ethical and Research Committee 231/08.

The individuals included in the study were those with a clear medical diagnosis of ALS, according to El Escorial revised criteria ${ }^{12}$, of both sexes and aged between 20 and 60 years of age. Any individual that refused to respond to any item of the ALSFRS-R/BR were excluded, as were those in the terminal phase of the disease.

After elucidated the study, the selected individuals agreed with the Terms of Consent.

In order to validate the scale, a translation of the English version of the ALSFRS-R was performed into Portuguese by two Brazilians with fluency in the English language and who were further conscious of the objectives of the research. The translations were duly compared and analyzed by the researchers and, after discussing the adaptations to Portuguese, a translated version was obtained ${ }^{13-15}$.

The scale was then translated back into English by an English native speaker with fluency in Portuguese that had never had any contact whatsoever with the scale. After this, this retranslated version was compared with the English original to check the veracity and thus conclude the production of a final version in Portuguese $\mathrm{e}^{13-15}$.

The ALSFRS-R/BR is based on 12 items with a scoring from zero to 4 and a total score ranging from zero to 48 , being such that a score of 48 presented normal functionality and zero, serious incapacity ${ }^{8}$.

The variables of each section of the scale are: speech, salivation and swallowing in bulbar function; handwriting, cutting food and handling utensils (with or without gastrostomy), dressing and hygiene in fine motor activi- ty; turning in bed and adjusting bed clothes, walking and climbing stairs in strong motor activities; and respiration, orthopnea and respiratory insufficiency in respiratory function?.

All the individuals were given the ALSFRS-R/BR during clinical visits and retested after 3 weeks, either in person or by telephone, with the purpose of analyzing the grammatical coherence and semantical, as well as to observe whether there had been a good understanding on the part of the interviewed individuals.

After the two applications of the scale, the scorings for each question were compared and validity analysis and reliability of the ALSFRS-R/BR were carried out.

The data were collated in the Statistical Package for the Social Sciences (SPSS) program, version 17.0. The following statistical tests were used: predictor measures, Pearson's coefficient, Alpha Conbrach, Student t-test and the intraclass correlation coefficient - ICC. The significance level was considered satisfactory to $5 \%$.

\section{RESULTS}

Of the 22 individuals that participated in the study, $88.2 \%$ presented signs of degeneration of upper and lower motor neuron, with an average time of injury of $25.36 \pm 19.66$ months. Of these individuals, $63.6 \%$ were males with a variation in age of between 22 and 79, with an average of $52.82 \pm 14.69$ years of age.

In order to characterize the sample, the predictor measures of the test and retest were compared. The results obtained showing the similarity between these two moments in which the scale was applied, except in the arithmetical average, where a minimal variation between the test $(29.59 \pm 8.06)$ and retest $(28.86 \pm 7.80)$.

In order to analyze the variation between the averages of the test and retest the Student t-test was used, based on a $5 \%$ level of significance, The value of $p$, in the study was 0,069 showing that there was no significant difference between the two moments in which the scale, was applied, thereby proving its reproductivity.

Pearson's correlation coefficient measured reliability through the linear correlation (positive or negative) between the test and retest of the ALSFRS-R/BR with a coefficient varying from -1 to 1 . The closer the result is to 1 or -1 , the stronger the linear relationship is between the two variables. In this study, a positive and statistically significant correlation coefficient was observed with $\mathrm{r}=0.975$ and $p=0.001$.

Regarding internal consistency, the correlations in the two moments of application of the scale were positive and statistically significant. The correlation was strong with alpha Conbrach of 0.934 .

The regressive analysis is a reliable-scale evaluation measure, and thus the intraclass correlation coefficient 
Table. Predictive measures of test-retest of the ALSFRS-R/BR

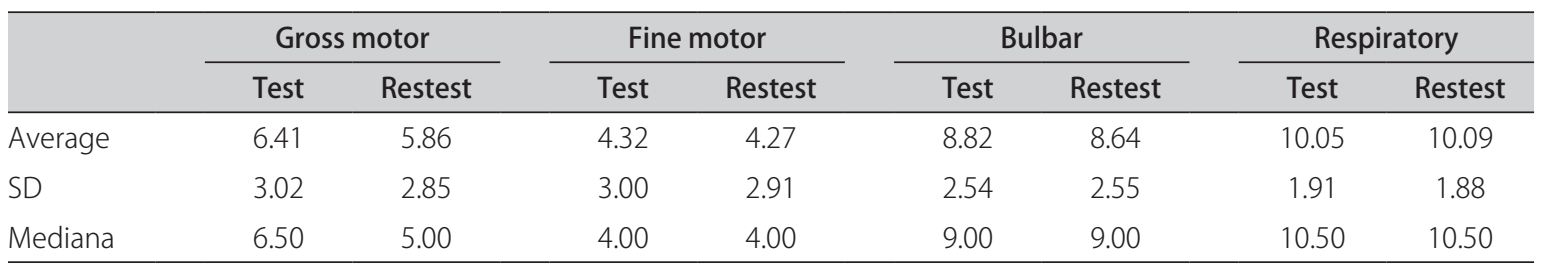

SD: standard deviation.

was used (ICC), which has a value that oscillates between -1 and 1 , returning the value 1 or -1 when these two variables are identical. In this study, there was a strong correlation, producing a result of 0.975 , and therefore, statistically significant. Table presents the predictor measures of the areas of ALSFRS-R/BR in the test and retest.

\section{DISCUSSION}

The application of the ALSFRS-R/BR scale upon 22 patients who are carriers of ALS in the Portuguese language showed itself to be reproducible and easily understood. This is due to the absence of any significant difference between the first test and subsequent retesting, as well as the high values of ICC $(\alpha=0.975)$ and of Pearson's correlation coefficient $(\mathrm{r}=0.975)$.

There was a need for some slight adaptations to the Portuguese version, after the back-translation, in order to make it grammatically and semantically coherent. Nevertheless, it was suggested by the translation board that such incoherent elements had in fact derived from probable error in the elaboration of the original scale.

No item of the scale was substituted or in fact showed itself to be incompatible with the social and cultural reality when compared with the original scale. Furthermore, a practicability and agility in the application of the scale was observed, deriving from the self-explanatory and easily understandable items, with the time of the application varying from between 5 to 10 minutes.

In this study, the most evident alterations that were noted were in the strong motor activities and bulbar functions than in any other. The discrepancy in the obtained values in each measure may be closely correlated to the rapid progress of the illness. These results corroborate with those of Hillemacher et al. ${ }^{16}$, who in 2004, evaluated, 41 patients and observed lower total scores of the scale in the bulbar function. Even so, they did not find significant differences in any of the evaluated items, as was the case of this present study, despite finding an increase in motor deficiency after 6 months.

Furthermore, a close correlation is observed in clinical practice between the 12 different items and the major complaints and limitations of individuals with ALS. A previous study verified that individuals with alterations in the strong motor activities showed a reduction in carrying out leisure activities, seeking out therapies to modify and adapt physical activities, as well as soliciting orientation concerning positioning and techniques in conserving energy ${ }^{17}$.

Apart from that, the ALSFRS-R/BR is a worthy instrument, being both of low cost and easy application and further proves to be a predictor of the progressive spread of the illness when compared to other functional scales, such as the Modified Norris Scale Dysphagia Outcome Severity Scale (DOSS) and Appel Amiotrophic Lateral Sclerosis Rating Scale (AALS) ${ }^{10,18-20}$. Other practical advantages that arise out of the application of functional scales compared to physical tests lie in the exclusion of the need for either measuring equipment or intensive training ${ }^{8,10,11}$.

The functional scale can also be applied to caregivers and can further be made over the telephone, without presenting any alteration in its reliability, as suggested by Mannino et al. ${ }^{8}$. Interestingly, these authors related that there was no significant difference in the results between the patient and the caregiver, except for the bulbar function and respiratory function. This fact could be explained by the subjectivity involved and the difficulty on the part of the caregiver to evaluate these specific items.

When the properties of the scale were verified in relation to the evaluation of the inter-evaluators, the study by Miano et al. ${ }^{11}$, found that all the evaluators produced very similar results. This indicates that the scale may be readily used and any change in evaluator will produce little if any effect.

This present study supplies a valid and useful tool for professionals in the health area, both for practical clinical use and scientific study involving individuals with ELA. Thus, it becomes possible to obtain reliable data about the daily limitations and progression of the illness, contributing to greater efficiency in both physiotherapeutic and pharmacological treatment.

In conclusion, the ALSFRS-R/BR proposed by this study did not require any cultural adaptation and showed itself to be reproducible and valid in Brazilian individuals with ALS. It constitutes an important instrument for monitoring the evolution of both the symptoms and limitation in carrying out routine daily activities. 


\section{REFERENCES}

1. Leight NP, Swash M, Iwasaki Y, et al. Amyotrophic lateral sclerosis: a consensus viewpoint on designing and implementing a clinical trial. Amyotrophic Lateral Sclerosis and Other Motor Neuron Disorders 2004;5:84-98.

2. Neudert C, Wasner M, Borasio G. Individual quality of life is not correlated with health-related quality of life or physical function in patients with amyotrophic lateral sclerosis. J Palliative Med 2004;7:551-557.

3. Shipe C, Zivkovic SA. Electrodiagnostic evaluation of motor neuron disorders. Am J Electroneurodiagnostic Technol 2004;44:30-36.

4. Kirby J, Halligan E, Baptista MJ, et al. Mutant SOD1 alters the motor neuronal transcriptome: implications for familial ALS. Brain 2005;128:1686-1706.

5. Cedarbaum JM, Stambler N. Performance of the Amyotrophic Lateral Sclerosis Functional Rating Scale (ALSFRS) in multicenter clinical trials. J Neurol Sci 1997;152(Suppl 1):S1-S9.

6. Moore DH, Miller RG, Wals Study Group, ALS CARE Study Group. ALSFRS as a measure of disease progression and survival. Amyotrophic Lateral Sclerosis Other Motor Neuron Disorders 2003;4:42-50.

7. Kauffmann P, Levy G, Montes J, et al. Excellent inter-rater, intra-rater, and telephone-administered reliability of the ALSFRS-R in a multicenter clinical trial. ALS 2007;8:42-46.

8. Mannino M, Cellura E, Grimaldi G, Volanti P, Piccoli F, La Bella V. Telephone follow-up for patients with amyotrophic lateral sclerosis. Eur J Neurol 2007;14: 79-84.

9. Cedarbaum J, Stambler N, Malta E, Fuller C, Hilt D, Thurmond B. The ALSFRS-R: a revised ALS functional rating scale that incorporates assessments of respiratory function. J Neurol Sci 1999;169:13-21.

10. Kollewe K, Mauss U, Krampfl K, Petri S, Dengler R, Mohammadi B. ALSFRS-R score and its ratio: a useful predictor for ALS-progression. J Neurol Sci 2008;275:69-73.
11. Miano B, Stoddard GJ, Davis S, Bromberg MB. Inter-evaluator reliability of the ALS Functional Rating Scale. Amyotrophic Lateral Sclerosis and Other Motor Neuron Disorders 2004;5:235-239.

12. Brooks BR. El Escorial revisited: revised criteria for the diagnosis of amyotrophic lateral sclerosis. Amyotrophic Lateral Sclerosis and Other Motor Neuron Disorders 2000;1:293-299.

13. Guillemin F, Bombardier C, Beaton D. Cross-cultural adaptation of health-related quality of life measures: literature review and proposed guidelines. J Clin Epidemiol 1993:46:1417-1432.

14. Guillemin F. Cross-cultural adaptation and validation of health status measures. Scand J Rheumatol 1995;24:61-63.

15. Beaton D, Bombardier C, Guillemin F, Ferraz MB. Guidelines for the process of cross-cultural adaptation of self-report measures. Spine 2000;25:3186-3191.

16. Hillemacher T, Grabel E, Tigges $S$, et al. Depression and bulbar involvement in amyotrophic lateral sclerosis. Amyotrophic Lateral Sclerosis and Other Motor Neuron Disorders 2004;5:245-249.

17. Trail M, Nelson ND, Van JN, Appel SH, Lai EC. A study comparing patients with amyotrophic lateral sclerosis and their caregivers on measures of quality of life, depression, and their attitudes toward treatment options. J Neurol Sci 2003;209:79-85.

18. Yoshino H, Kimura A. Investigation of the therapeutic effects of edaravone, a free radical scavenger, on amyotrophic lateral sclerosis (Phase II study). ALS 2006;7:247-251.

19. Kidney D, Alexander M, Corr B, O'Toole O, Hardiman O. Oropharyngeal dysphagia in amyotrophic lateral sclerosis: neurological and dysphagia specific rating scales. Amyotrophic Lateral Sclerosis and Other Motor Neuron Disorders 2004;5:150-153.

20. Voustianiouk A, Seidel G, Panchal J, et al. ALSFRS an APPEL ALS scores: discordance with disease progression. Muscle Nerve 2008;37:668-972. 